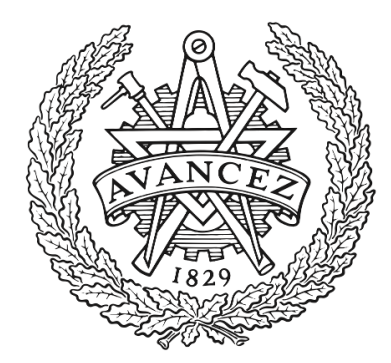

CHALMERS

\title{
Nudging bicyclists towards a safer behavior -Experiences from the MeBeSafe project
}

Downloaded from: https://research.chalmers.se, 2023-04-26 15:27 UTC

Citation for the original published paper (version of record):

Wallgren, P., Karlsson, M., Bergh Alvergren, V. (2020). Nudging bicyclists towards a safer behavior -Experiences from the MeBeSafe project. Proceedings of 8th Transport Research Arena TRA 2020

N.B. When citing this work, cite the original published paper. 


\title{
Rethinking transport
}

\section{7-30 April 2020}

Proceedings of 8th Transport Research Arena TRA 2020, April 27-30, 2020, Helsinki, Finland

\section{Nudging bicyclists towards a safer behavior -Experiences from the MeBeSafe project}

\author{
Pontus Wallgren ${ }^{\mathrm{a} *}$, MariAnne Karlsson ${ }^{\mathrm{a}}$, Viktor Bergh Alvergren ${ }^{\mathrm{a}}$ \\ ${ }^{a}$ Chalmers University of Technology, Gothenburg SE-41296, Sweden
}

\begin{abstract}
The European union's official cycling strategy states that bicycle use should increase by 50 percent in ten years while at the same time halving the amount of deaths (ECF, 2019). It is therefore highly important to find safety increasing measures that are both acceptable for bicyclists and that actually work. The Horizon 2020 project MeBeSafe is investigating if nudging can be a fruitful way towards safer traffic behaviour of car and truck drivers, as well as cyclists. This paper reports on a series of quasi-experimental studies that investigated if nudging can affect bicyclists' speed as well as trajectory. The project has so far showed that visual nudges have a great potential for affecting speed and trajectory, while haptic nudges seems to have little effect.
\end{abstract}

Keywords: Nudging; Cycling safety; Speed reduction

\section{Introduction}

Eight percent of those killed on EU roads are riding a bicycle, while just two percent of the travelled passenger kilometres are made on bikes. (European Commission, 2017; European Commission, 2018; Steenberghen et al., 2017). Furthermore, the share of killed cyclists is still on the rise (European Commission, 2018). A Swedish study found that eight of ten car-bicycle accidents happen in intersection scenarios, with a majority of car drivers not spotting the cyclist before the collision (Isaksson-Hellman \& Werneke, 2017). While the obvious solution might be to get rid of car-bicycle intersections altogether, a first step towards less accidents could be to make people (on bikes and in cars) slow down and increase their watchfulness in dangerous intersections.

While measures such as speed bumps, chicanes, and rumble stripes have been found to have effect on car drivers, previous research show no such effects on bicycle riders (e.g. Ljungblad, 2017). Moreover, such measures are highly disliked by the cyclists and are perceived to decrease safety.

As a contrast, the Horizon 2020 project MeBeSafe is trying to use the concept of nudging instead of hard measurements to encourage people to adopt a more safe traffic behavior. Nudging was first described by Thaler and Sunstein (2008) and is a way of predictably altering people's behaviour on a subconscious plane without forbidding any options. It can be described as more or less a gentle push in the right direction. For bicyclists, the goal is to nudge people so that they go slightly slower in dangerous intersections while not disturbing the flow and

\footnotetext{
* Corresponding author. Tel.: +46-31-7721397;

E-mail address: pontus.wallgren@chalmers.se
} 
feeling of freedom that is key elements of the cycling experience.

\section{Method}

So far, two experimental studies have been performed, one on visual nudges with 93 test participants cycling in real traffic conditions, and one with haptic nudges with 16 test participants cycling in an experimental setting. For both tests, participants that were cycling at least a couple of days per week were recruited through social media as well as through flyers attached to bikes all over the city. The average age of the participants was 37.2 years (span $18-75), 59 \%$ male and $41 \%$ female. $88 \%$ had a driving licence for cars. $93 \%$ of the participants used a bicycle at least several times a week, while $52 \%$ stated that they biked every day of the week. Most of the participants (73\%) also claimed that they used their bicycles all year round.

The test participants used their own bikes in the tests, and video, GPS, and accelerometer data were recorded by the means of a Garmin Virb Ultra action camera. In particular the speeding behavior before and during the nudges were investigated (Figure 1).

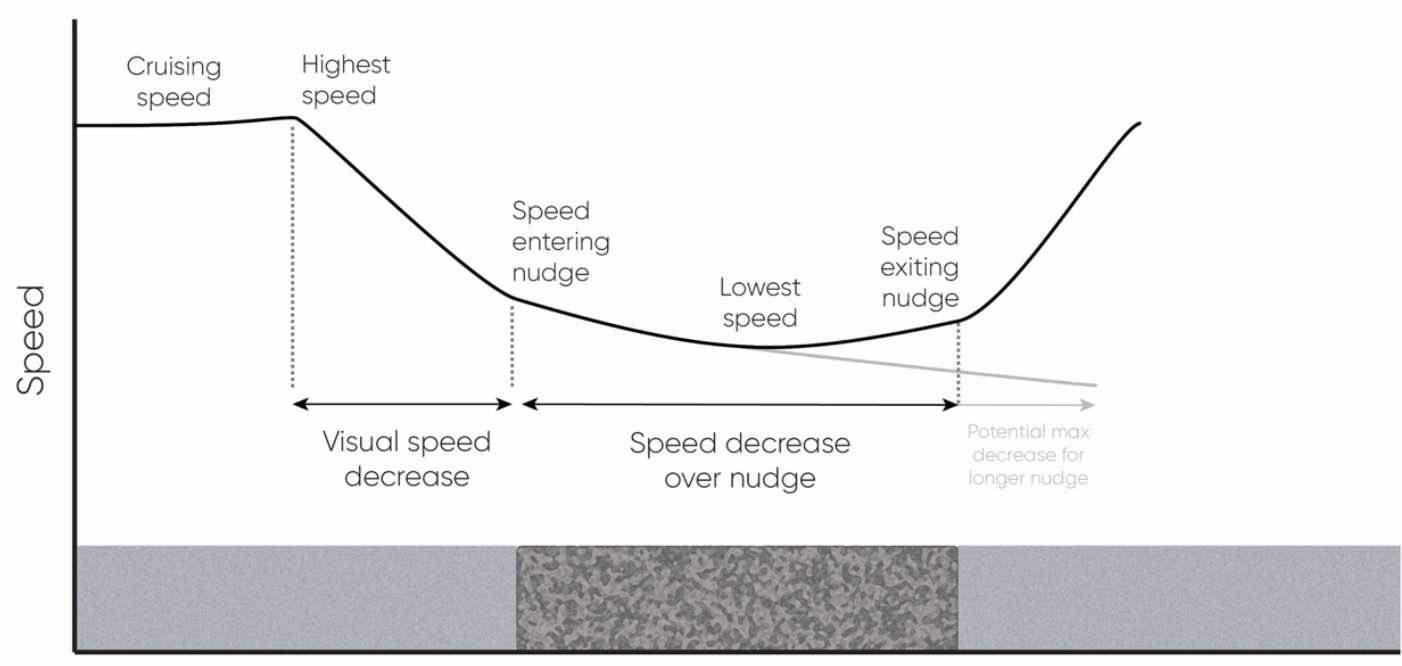

Distance

Fig. 1 Speeds measured before and over the nudge

Both the visual and the haptic nudges were designed in an iterative design process with theoretical investigations, idea generation workshops with cycling experts, concept testing, and development, leading up to a number of nudges that have a potential to affect speed.

Three different types of visual nudges have been tested, transverse stripes of decreasing distance, visually narrowing the lane, and electronic signs showing speed as well as messages that changed with speed. Each nudge was tested in two versions, one being more explicit than the other (Figure 2). Each nudge was implemented before an intersection on real cycle lanes in the Gothenburg city center, and results in terms of speed reduction was compared to the reduction of speed in the intersection when no nudge was present. 


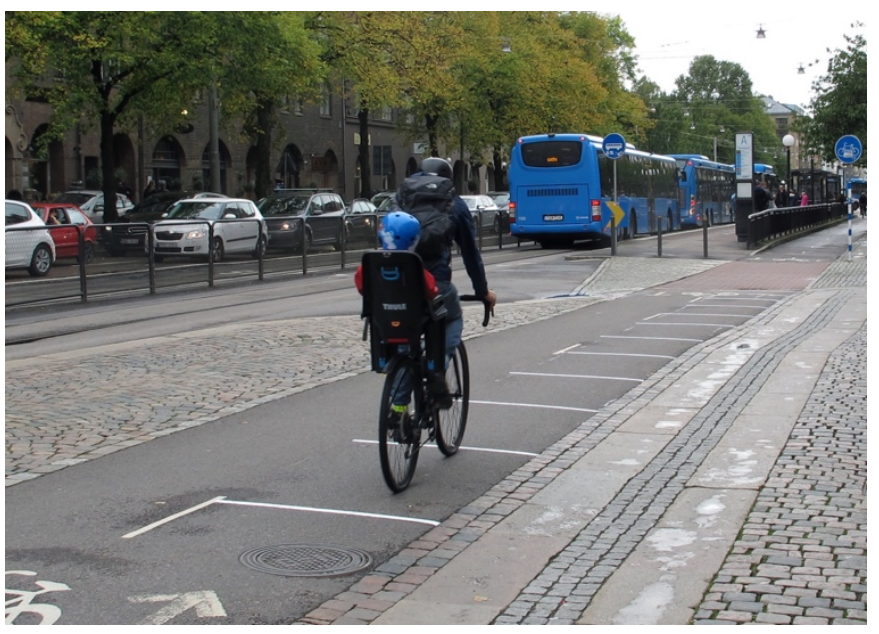

Fig. 2 One of the tested visual nudges, a series of perpendicular lines with decreasing distance to give the illusion of speed.

The haptic nudges were as previously described tested in a more experimental setting and with fewer participants. The tested nudges consisted of materials with different structure and softness, as well as bumps and slopes of different designs. The tested haptic nudges were being considered much less developed and potentially unsafe to try out on real bike lanes with unknowing bicyclists (Figure 3). Consequently, the tests were performe at an old abandoned ferry terminal, using the lanes that used to lead to the ferries.


Fig. 3 The different haptic nudges tested; a soft asphalt, a squishy material, soft rubber strips, a rough surface, a slope, and a soft bump

\section{Results \& Discussion}

The results show that the visual nudges decreased the average speed (on top of baseline) with 12-20 percent. While the electronic signs were the most effective, they were also found to take a lot of the cyclists' attention away from the traffic situation and they were only effective in the cases where the test participant noticed the sign. The nudges with lines on the other hand were as effective if the test participant noticed it or not, making us believe that they 
actually worked subconsciously as a nudge should. Moreover, painting lines is a very cost-efficient solution compared to variable speed signs. The transverse lines had the added benefit, over the visual narrowing of the lane, that it didn't seem to take attention away from the traffic situation. A final result from the tests with visual nudges were that almost every one of the participants stated, without prompting, that they really appreciated that the lines were not protruding as traditional road markings and therefor did not cause uncomfortable bumps.

The results from the study of haptic nudges on the other hand showed much less effect on speed (less than $5 \%$ speed reduction). Moreover, the participants had a lot of objections to the different tested nudges. The solutions were considered unsafe and/or uncomfortable by the participants, and there were also concerns about the environmental impact of the softer materials such as rubber. While there were no solution that and stood out as more disliked or more liked by every participant, there was a correlation between regarding a solution as unsafe and uncomfortable on one hand and slowing down on the other, which leads us to believe that haptics may be a difficult way to get user acceptance for a speed reducing measure. Finally, all tested nudges were considered by the participants to be impossible to maintain, especially during wintertime.

The conclusion from the tests performed so far in the project was therefor to continue testing the nudge employing transverse stripes to create an illusion of speed. During autumn 2019 this nudge will be tested over a longer period of time (three months) in at least two different locations to see if the effect holds over time.

If the effect holds over time, it will be a very effective way to slow down bicyclists in dangerous intersections and consequently increase bicycle safety.

\section{Acknowledgements}

The research presented in this paper was financed by the European Union, Horizon2020

\section{References}

ECF. (2019). EU cycling strategy. [online] Available at: https://ecf.com/eu_cycling_strategy [Accessed 2 May 2019].

European Commission. 2017 road safety statistics: What is behind the figures?. Brussels, 2018.

European Commission. Cyclists - Mobility and transport. Brussels, 2018. Available at: https://ec.europa.eu/transport/road_safety/users/cyclists_en [Accessed 18 Dec. 2018].

Isaksson-Hellman, I., and Werneke, J. "Detailed Description Of Bicycle And Passenger Car Collisions Based On Insurance Claims", Safety Science 92 (2017), 330-337, doi:10.1016/j.ssci.2016.02.008

Ljungblad H., "Taktila farthinder för cyklister - effekter på hastighet och cyklisternas upplevelse”, Koucky \& Partners (2017) (In Swedish, available at the Swedish Road Administration's web, trafikverket.se)

Steenberghen, T., Tavares, T., Richardson, J., Himpe, W. and Crabbé, A. Support study on data collection and analysis of active modes use and infrastructure in Europe. Brussels: 2017.

Thaler, R., Sunstein, C. (2008) Nudge :improving decisions about health, wealth, and happiness New Haven : Yale University Press, 